\title{
Optimum Load Frequency Control in Power System using BFOA and CA
}

\author{
Pawar Shalikram Motiram ${ }^{1}$, Dr. Subhash Shankar Zope ${ }^{2}$ \\ ${ }^{I}$ Ph.D. Scholar, School of Engineering, SSSUTMS, Sehore (M.P), India \\ ${ }^{2}$ Former Principal, Vice Principal and HOD, Electrical Engg. Dept.J.T.M. Polytechnic Faizpur \\ Jalgaon (Maharashtra State), India
}

Received on: 22 August, 2021

Revised on: 26 September, 2021

Published on: 28 September, 2021

\begin{abstract}
In today's world where the demand for energy is increasing day by day, interconnected power systems have been introduced to meet the energy demand resulting from globalization. One of the most important parameters for testing in electrical networks is frequency. A change in load in any area of the power system in interconnected power systems means that other areas of the connected power system are affected by frequency and power. For this reason, the load frequency control problem is one of the most important issues for power systems. This paper proposes the performance of P, PI and PID controllers in two-area power systems tested with two optimization algorithms; Bacterial Foraging Optimization and Cultural Algorithm. Simulation and modelling are performed from the MATLAB-Simulink environment and the results are compared.
\end{abstract}

Keywords-AGC, BFOA, CA, EPS, LFC, P, PI, PID.

\section{I- INTRODUCTION}

$\mathbf{T}$ hroughout the years, it has been sought for the Electric Power System (EPS) to reach an ever higher degree of reliability, for which a large number of methodologies have been proposed on its control and monitoring, both from the point of view of centralized control, as well as from the point of view of distributed control [1]. The trend in recent years being distributed control, a methodological proposal that facilitates:

1. The coordinated operation of the large number of dynamic components of the system,

2. The insertion of distributed generation,

3. The increase in efficiency; and

4. The operation of interconnected systems in which more than one.

This paper presents a valid option for the operation and monitoring of the EPS through the implementation of distributed controllers that work cooperatively, thus obeying the law of natural synchronization present in the EPS (all this justified by its characteristic of being an interconnected system). Which leads to its operation allowing actions on the load-frequency control in a decentralized way. Thus, they have potential benefits such as improving the reaction capacity of the EPS in comparison with the traditional AGC (Automatic Generation Control) scheme, by facilitating the rapid return to a new state of equilibrium between generation and demand after different variations arise [2]. 


\section{International Journal of Innovations in Engineering and Science, www.ijies.net}

Indeed, the purpose of all the studies carried out in the electricity sector look for valid alternatives that allow to increase the autonomy of operation [1] - [2], increase the reliability of the system, improve performance in response to different events, raise levels quality of the energy supplied, etc., and in this case the implementation of a distributed architecture within the electrical system is capable of solving many of the needs, all this thanks to the philosophy of dividing the efforts in a balanced way between each and every one of the local controllers to carry out the control and monitoring tasks. For this, the development of this paper will provide a valid control alternative for the EPS from the perspective of distributed control, initially studied from mathematical rigor with its modeling and validated using simulation tools available in engineering, therefore it serves as a base study for new proposals for distributed control applied to the electricity sector.

In today's world where the energy need is increasing day by day, interconnected power systems have been established in order to meet the energy need with the effect of globalization. So much so that a country does not only want to create interconnected systems within itself, but also wants to exchange power with neighboring countries at the most affordable costs [3].

Necessary arrangements and adjustments need to be made to connect interconnected systems to each other. First of all, all systems connected to the interconnected system must be stable within themselves. However, the frequencies of all systems must be the same and controllable.

Frequency is one of the most important parameters to be controlled in power systems. In order for a power system to work stable, the frequency must remain constant. This is only possible with the balance of power. The power balance mentioned here is the situation where the sum of active power generated and active loads, losses and active powers flowing on the connection lines of the system are equal to each other. When the balance is disturbed, deviations in frequency begin to occur [4]. When energy production increases in an interconnected system, or in other words, when the energy requirement decreases, the frequency of the interconnected system will start to increase. Likewise, if the production decreases or the energy need increases, the frequency of the system will decrease. In order to keep the system frequency at the desired value, the turbines are controlled as speed regulators in the generators. As a result, the process of adjusting the electricity produced in power systems and the frequency according to the changing consumption is called Load Frequency Control (LFC) [5].

If the amount of electricity consumed per capita indicates the level of development of a country, then the quality of this consumed energy is now an important criterion. System frequency and voltage are the two most important parameters in determining power quality. Frequency takes longer to control voltage and is the dominant parameter in an electrical system. For this reason, the parameter that mainly needs to be controlled in the system is frequency [6]. An interconnected electrical system consists of many sections that work together. A change in power (supply or demand) that occurs in one of these areas will affect the other connected fields in terms of frequency and power. In addition, the characteristic of the communication line between fields connected to the electrical system is another factor that influences the frequency variation. When the frequency variation of the power system exceeds the specified limits, it can lead to serious problems of instability in the power system, shutdown of the power plants connected to the system, and, at a later stage, to system collapse (black - external). In this case, the region served by the system will be left without electricity and there will be huge economic losses. In Turkey - 77 million in 2015 and 150 million in 2012, in Bangladesh in 2014 - the collapse of the system, which affected 620 million people in India, are examples of this situation. [7] Therefore, control of the frequency of replenishment of the balance today is a very important issue, given the area of influence and the associated economic losses.

The creation of many algorithms from the 1970s to the present has been inspired by the behavior of systems / living things in nature, such as nature, society, culture, politics and humans. The term heuristic is used to refer to the combination of rules and randomness of simulated natural phenomena. In recent years, heuristic methods have attracted the attention of researchers from many disciplines. This interest has increased further with its application to solving real-world optimization problems in many areas such as trade and industry, especially in engineering applications. Different metaphors are used for each heuristic search optimization. For example, the Particle Swarm Optimization (PSO) algorithm, introduced in 1995, simulates the behavior of flocks and provides optimized results for tuning the PID controller to control the loading rate [8]; Harmony Search Algorithm (HSA) and Cuckoo Search Optimization have also been used to optimize the fuzzy PID by detecting 


\section{International Journal of Innovations in Engineering and Science, www.ijies.net}

situations where the match is perfect [9]; The Bacterial Foraging Optimization Algorithm (BFOA) simulates the process of finding nutrients by bacteria with the lowest energy [10]. The artificial bee colony (ABC) algorithm was used to optimize the PID and simulate the behavior of a swarm of honeybees in search of food [11]. LFC control based on the firefly algorithm (FA) is proposed to be implemented according to their idealization of the light-emitting characteristics of fireflies [12]. The Gravity Search Algorithm (GSA) was created based on the concept of the interaction of masses and the laws of gravity [13]. Teaching and Learning-Based Optimization (TLBO), announced in 2011, mimics the teachinglearning process of a teacher and student in the classroom [14]. The Krill Herd (KH) algorithm, announced in 2012, works by simulating the catch of a krill herd in response to specific biological and ecological processes [15] [16].

Conventional PID controllers are used as generalized controllers for automatic generation control in power systems [7] [17] [18]. Numerous studies have been conducted to determine the most appropriate PID parameters [19] [20] [21] [22]. While most of the methods described in the literature seem to be effective for determining controller gains, some have problems such as slow convergence and some get stuck at local minima during the global minimum search phase. The Cultural Algorithm (CA) and the Bacterial Search Optimization Algorithm (BFOA) are heuristic methods that have shown the best performance with these aspects [23] [24].

This paper proposes a comparative analysis of two optimization methods, the cultural algorithm and BFOA, to determine the optimal values of the parameters of the regulator that controls the frequency in a two-area electrical system. MATLAB-Simulink tool is used for model implementation and simulation. The second section presents proposed method for controlling the load frequency. The simulations and results are presented in the third section, and finally the fourth section provides concluding remarks.

\section{II -PROPOSED METHODOLOGY}

\section{A. Power System Model}

In a power plant with a rotating machine, potential / kinetic energy is converted to mechanical energy by turbines and then to mechanical energy to electrical energy in generators. A simplified equation of motion for this principle:

$$
T_{m}-T_{e}=J \frac{d \omega}{d t}
$$

It is written in the form. Here $T_{m}$ is the mechanical moment, $T_{e}$ is the load moment, $J$ is the moment of inertia and $\omega$ is the angular velocity.

The areas connected by connecting lines constitute an interconnected electrical system. Each area energizes its users, and the connecting lines connecting the fields allow energy to flow between areas. Therefore, when a sudden load change occurs in one area, it affects the frequency values in other areas and the power change values of the connecting lines. The controller needs transient information for each zone to restore the system to the desired steady-state value. Therefore, one can reset the system frequency to the desired steady-state value. Disregarding the losses occurring in the lines connecting the two separate areas, the power in the connecting line can be written as follows:

$P_{\text {line12 }}=\frac{\left|V_{1}\right| \cdot\left|V_{2}\right|}{X_{12}} \sin \left(\delta_{1}-\delta_{2}\right)$

Here, $V_{1}$ and $V_{2}$ represent the amplitude of the $1^{\text {st }}$ and $2^{\text {nd }}$ area voltages respectively, the phase angles $\delta_{1}$ and $\delta_{2}$, and $X_{12}$ the connecting line impedance. Phase angle changes for each area:

$$
\Delta \delta=2 \pi \int \Delta f d t
$$

When written in the form of power change between areas will be:

$$
\begin{aligned}
& \Delta P_{12}=\frac{\left|V_{1}\right| \cdot\left|V_{2}\right|}{X_{12}} \cos \left(\delta_{1}-\delta_{2}\right)\left(\Delta \delta_{1}-\Delta \delta_{2}\right) \\
& =T_{12}\left(\Delta \delta_{1}-\Delta \delta_{2}\right)
\end{aligned}
$$

Synchronizing moment coefficient of the line expressed in the form:

$$
T_{12}=\frac{\left|V_{1}\right| \cdot\left|V_{2}\right|}{X_{12}} \cos \left(\delta_{1}-\delta_{2}\right)
$$

When the moment coefficient is written instead in equation (4), the connection line power change will be:

$$
\Delta P_{\text {tie }}=T_{12}\left(\Delta \delta_{1}-\Delta \delta_{2}\right)
$$

As a result of a power change of $\Delta P_{L}$ in the system, the frequency deviation and the related power change and the area control error (ACE) are as follows, respectively.

$$
\Delta f=\frac{-\Delta P_{L 1}}{\frac{1}{R_{1}}+\frac{1}{R_{2}}+D_{1}+D_{2}}
$$




\section{International Journal of Innovations in Engineering and Science, www.ijies.net}

$$
\begin{gathered}
P_{\text {tie }}=\frac{-\Delta P_{L 1}\left(\frac{1}{R_{2}}+D_{2}\right)}{\frac{1}{R_{1}}+\frac{1}{R_{2}}+D_{1}+D_{2}} \\
A C E_{1}=\Delta P_{\text {tie }}+B_{1} \cdot \Delta f_{1} \\
A C E_{2}=B_{2} \cdot \Delta f_{2}+a_{12} \cdot \Delta P_{\text {tie }}
\end{gathered}
$$

The transfer functions of each block in the two-area power system model are given below.

Regulator

Turbine

$$
G_{g 1}(s)=G_{g 2}(s)=\frac{K_{h}}{T_{h} \cdot s+1}
$$

$$
G_{t 1}(s)=G_{t 2}(s)=\frac{K_{t}}{T_{t} \cdot s+1}
$$

Connection Line

$$
G_{t l}(s)=\frac{2 \pi \cdot T_{12}}{s}
$$

Intermediate Heater

Power System

$$
G_{r h 1}(s)=G_{r h 2}(s)=\frac{\left(K_{r 12} \cdot T_{r 11}\right) \cdot s+1}{T_{r 1} \cdot s+1}
$$

$$
G_{p s 1}(s)=G_{p s 2}(s)=\frac{K_{g}}{T_{g} \cdot s+1}
$$

The system using the model is widely used in the literature [25] [26] and the parameters in these studies are taken as the same. The block diagram of the two-area power system to be controlled according to these equations is given in Figure 1.

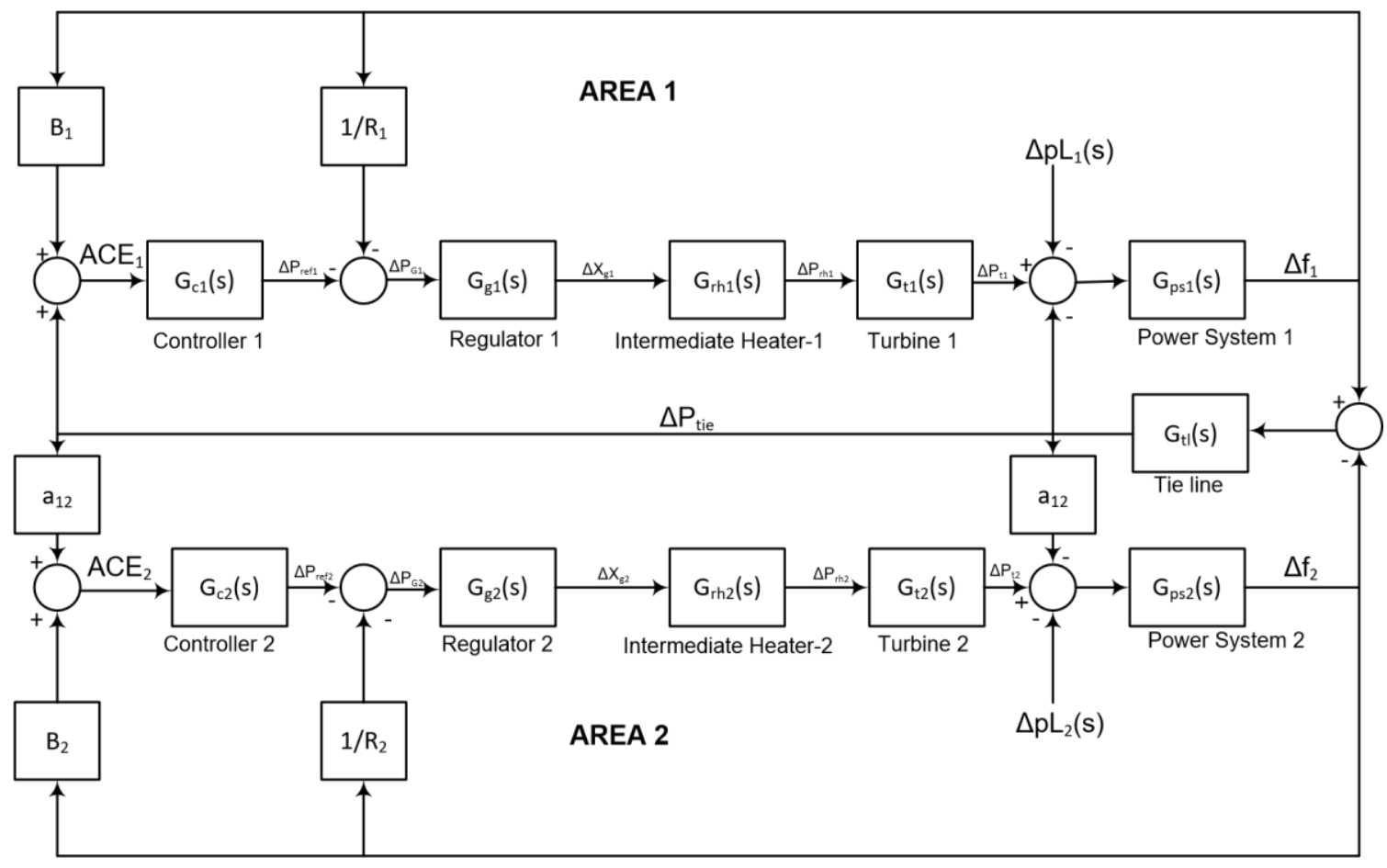

Fig 1- Two-zone power system model [26]

\section{B. Load Frequency Control Using P, PI and PID Controller}

The process of increasing or decreasing the power produced is realized by speed regulators controlled by suitably designed controllers. Integral controllers are the most commonly used types of controllers to perform in the literature. In addition, PI, PID, artificial neural networks, fuzzy logic type controllers, fuzzy PI, fuzzy PID and genetic algorithms are also frequently used controller types.

In load frequency control operations performed with PI controllers, it gives good step responses for low-order linear systems, but it is slow in adaptation to a change that may occur in the interconnected network due to the nonlinearity of the interconnected power systems and causes a steady state error. In this paper, the performance of the P and PI is compared with one of the most used controller i.e. PID controller, in two-area power systems.

Different PID Actions: When the process is digital, we will speak of digital control. All signals are digital and sampled at period $\Delta$.

To seek a control law one must thus calculate the necessary corrector. In numerical control, it is a question of producing $u(k)$.

\section{Proportional (P) Controller}




\section{International Journal of Innovations in Engineering and Science, www.ijies.net}

The proportional controller improves system response time. The control of this controller is proportional to the error. Its transfer function:

$$
u(k)=K_{c} \cdot \varepsilon(k)
$$

$K_{c}$ : is the proportionality coefficient to be adjusted manually.

\section{Proportional Integral (PI) Controller}

For a purely integral controller, the dynamic speed is relatively high. On the other hand, the proportional controller reacts immediately to deviations in the configuration, but cannot completely eliminate the static error. The combination of proportional and integral actions combines the advantage of the "P" controller, which is quick response to command deviations, with the advantage of the "I" controller, which is accurate compensation with controlled amount.

The regulation of this controller is proportional to the error but also proportional to the integral of the error. Then add the proportional controller to the generated command, the sum of the errors made over time.

The control algorithm of the PI controller is:

$$
u(k)=K_{c} \cdot \varepsilon(k)+T_{i} \cdot \sum \varepsilon(k)
$$

With $T_{i}$ : integral time constant.

\section{Proportional Integral Derivative (PID) Controller} PID controller is obtained by the association of three actions; P, I and D. The parameters of the PID controller are: the gain $K_{P}$, the integral time $T_{i}$ and the derivative time $T_{d}$, the times being expressed in seconds.

Control algorithm of the PID controller is expressed as:

$$
u(k)=K_{c} \varepsilon(k)+T_{i} \sum \varepsilon(k)+T_{d}(\varepsilon(k)-\varepsilon(k-1))
$$

The PID controller consists of three parameters $K_{P}, K_{I}$ and $K_{D}$.

$$
u(t)=K\left(e(t)+\frac{1}{T_{1}} \int_{0}^{t} e(t) d t+T_{D} \frac{d e(t)}{d t}\right)
$$

The error signal feeding the PID controller is divided into steady state and transient fault. Since the PID parameters $K_{P}, K_{I}$ and $K_{D}$ are fixed, they cause both temporary and permanent state errors to continue. Choosing higher values for transient error and lower parameter values for steady state error is a technique that can be used to solve the problem. Compared to the permanent situation, the temporary situation happens in a shorter time. In order to improve the performance of frequency change $(\Delta \omega)$ and link line power flow $\left(\Delta P_{t i e}\right)$ characteristics in the power system, the steady state error can be further reduced by increasing the $K_{P}, K_{I}$ and $K_{D}$ values according to the step response.

\section{Objective Function}

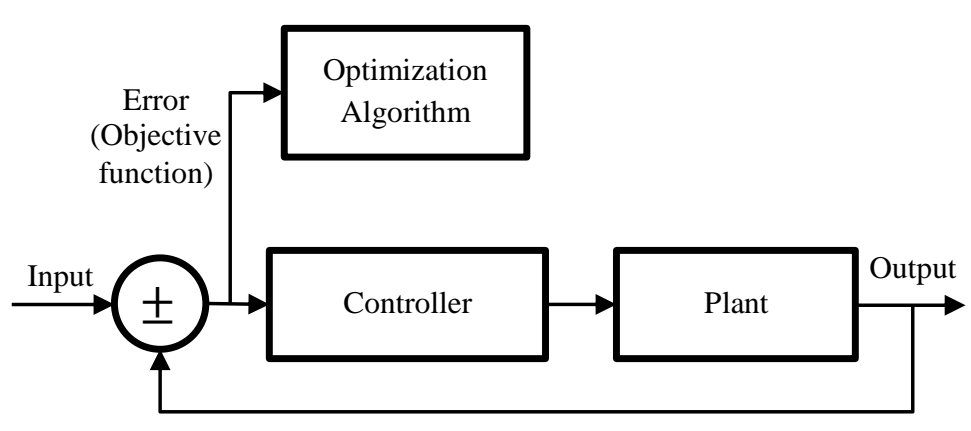

Fig 2- Optimization algorithm applied to controllers

For the algorithm defined above, the objective function is given by:

$$
\text { Objective Function }=\int \operatorname{error}(t) d t
$$

This objective function is minimized by using Cultural Algorithm and BFOA algorithm.

\section{Optimization Algorithms}

The increase in the amount of information used with the development of technology has made the problems multi-dimensional. Accordingly, the speed and quality of the solution to the problems gained importance. The optimum and fast solution of these problems is a situation that scientists are working on. At this point, the concept of optimization has emerged.

The inadequacy of classical optimization algorithms in solving multi-dimensional and complex problems has 


\section{International Journal of Innovations in Engineering and Science, www.ijies.net}

led to the development of heuristic algorithms. There are several ways to classify heuristic algorithms. In algorithms inspired by nature, general convergence is achieved by simulation of physical and ecological processes in nature and the algorithm's own optimization mechanisms, and effective results are obtained.

\section{Cultural Algorithm}

The cultural algorithm was originally developed by Robert Reynolds [27] as an extension of the evolutionary algorithm. The operation shown in Figure 3 is described in the following model. The algorithms operate in two spaces: the population space and the belief space. In the first space, there are several individuals, each of which has a set of independent characteristics, each of which is assessed in accordance with a matching function, as in any evolutionary algorithm. Over time, these individuals may have several offspring. The second space is a repository of knowledge that people acquire from generation to generation. The information contained in this space should be available to everyone. The belief space is updated after each iteration with the best person from the population, the knowledge category of the belief space can influence the components of the population through an influence that can affect the population by changing the genome or actions of the individual. To connect the two spaces, communication protocols are established that define rules for the types of information that spaces must exchange.

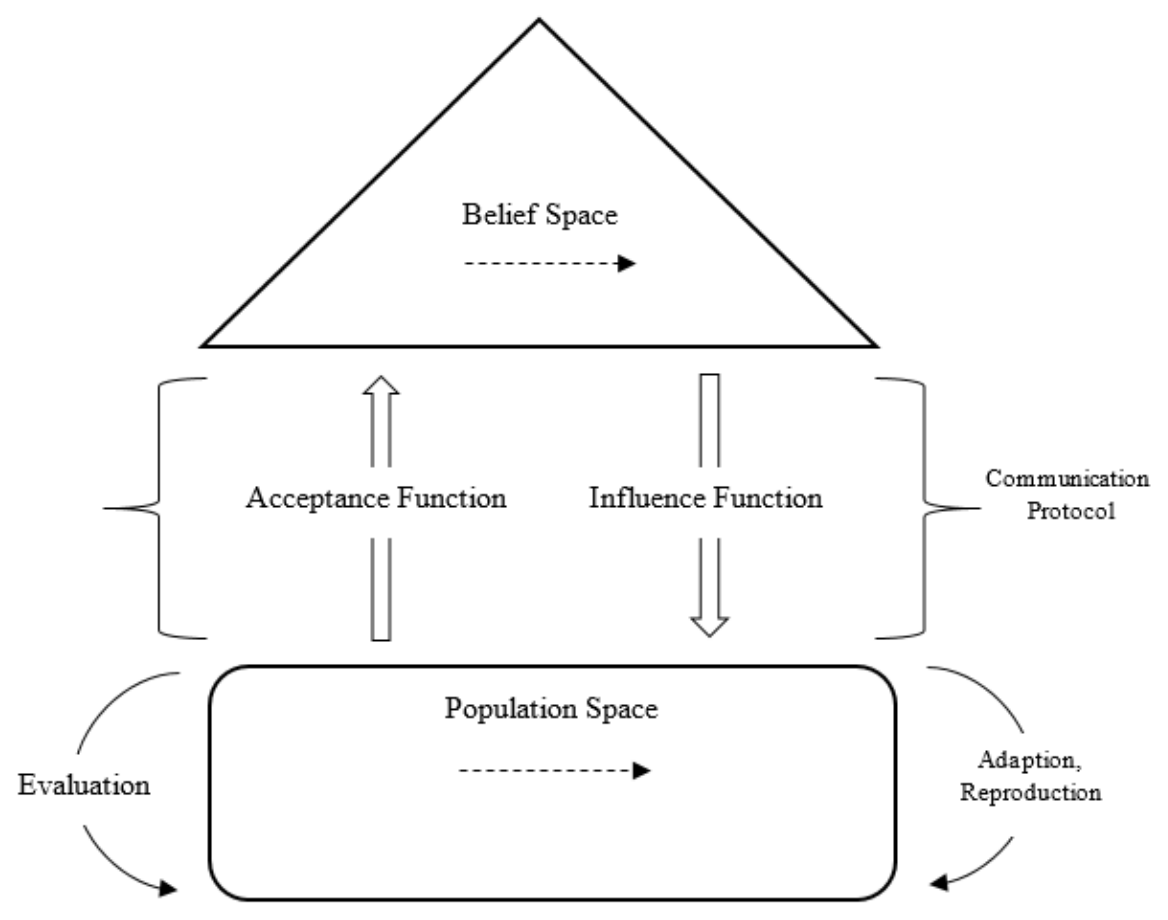

Fig 3-Structure for cultural algorithm [28]

The pseudo code used for the culture algorithm looks like:

- Initialize the populated space.

- Initialize a belief space

- Repeat until final conditions are met.

- Perform individual actions in the community

- Rate each person with the fitness function

- Choose parents to reproduce a new generation of children

- Let the belief space alter the genome of the offspring using the influence function
- Upgrade a belief space using the acceptance feature that allows a better person to influence a belief space

\section{Bacterial Foraging Optimization Algorithm}

The BFOA, proposed by Passino [29], is an optimization algorithm based on the idea of swarm intelligence and models the behavior of the bacterium Escherichia coli. Found in the human intestine, E. coli uses flagella to move around and is probably the microorganism best understood by science. The algorithm represents the search for these bacteria for nutrients or the removal of toxins, the interaction between bacteria and their reproduction. While changing positions in the search 


\section{International Journal of Innovations in Engineering and Science, www.ijies.net}

space, which can have several dimensions, each individual in a population of bacteria encounters a certain combination of nutrients and toxins. In the optimization procedure, this combination is the value of the objective function that is intended to maximize or minimize when the state variables are the coordinates of the bacterium's position in a given iteration.

Four processes are implemented to model the behavior of the bacteria population while conducting the search. They are:

- Chemeotaxis,

- Swarming (the interaction between individuals in a swarm),

- Reproduction

- Elimination and Dispersion.

Chemotaxis: The bacteria's food search strategy is of the saltatory type and is directly related to its mobility. Among the types of bacteria, there are those that are independent of flagella to move and those that move through flagella, such as Escherichia coli. Biologists discovered in the mid-1970s that the movement of bacteria was not random, but rather attracted to or repelled from it by means of stimuli and called this behavior chemotaxis [29].

E. coli can move in two different ways: advancing in one direction or changing direction in a counterclockwise direction to advance (or swim), and clockwise to change direction (or tumble). It alternates between these two states during its life span, randomly changing direction, which allows the space to be scanned for nutrients. If the bacterium detects a gradient of nutrients, and advances towards the highest concentration, it tends to spend more time advancing than changing direction.

In this step of the algorithm, the change in the position of the bacteria is done by equation (21), where $\Theta^{i}$ is the position of the $i^{\text {th }}$ bacterium in the population, $\phi(j)$ is the random direction taken after the somersault, $C(i)$ is the size of the advance taken in the direction $\phi(j), j$ is the stage of the chemotaxis process, $k$ is the stage of the reproduction process, $l$ is the stage of the elimination and dispersion process.

$\Theta^{i}(j+1, k, l)=\Theta^{i}(j, k, l)+C(i) \times \phi(j)$

The cost $J$ is calculated, given by the objective function for the bacterium $i$ in the new position and the swarm interaction with the other bacteria is performed. If the cost of position $\Theta^{i}(j+1, k, l)$ is better than the cost of position $\Theta^{i}(j, k, l)$, the bacterium makes another size advance $C(i)$ in the same direction $\phi(j)$. This process defines the scanning of the bacteria in a gradient and is repeated as long as the cost of the new position is better than the previous one or if the number of steps taken is less than $N_{S}$, initially adjusted.

The chemotaxis process is done for each of the $N_{\text {pop }}$ bacteria in the population and is repeated $N_{c h}$ times.

Swarming: Several types of bacteria show swarm behavior. In the case of $\mathrm{E}$. coli, when subjected to a stress condition, it releases a signal in the direction of the other bacteria. This signal can attract or repel the others, according to the situation in which it is submitted. In the optimization process, this interaction causes the value of the objective function for a bacterium, given by $\operatorname{cost} j$, to receive a decrease (considering minimization as a standard) if it is attracting others or an increase if it is repelling.

Equation (22) shows the change caused in the cost value, where $J_{c c}$ is the attraction / repulsion factor that bacteria $i$ causes in the population $P$. A new interaction between individuals is made with each change of position.

$$
\begin{aligned}
& J(i, j+1, k, l)=J(i, j+1, k, l)+J_{c c}\left(\Theta^{i}(j+\right. \\
& 1, k, l), P(j+1, k, l))
\end{aligned}
$$

This change in the values of the objective function creates a region in the search space around each bacteria. The other bacteria are attracted or reread according to that region. The value $J_{c c}$ is given by equation (23), where $p$ is the number of dimensions of the decision space, $d_{\text {attract }}$ is the depth and $w_{\text {attract }}$ is the width of the attractiveness region, $h_{\text {repel }}=d_{\text {attract }}$ is the height and $w_{\text {repel }}$ is the width of the repulsiveness region.

$$
\begin{aligned}
& J_{c c}(\Theta, \mathrm{P}(j, k, l))=\sum_{i=1}^{N_{\text {pop }}} J_{c c}^{i}\left(\Theta, \Theta^{\mathrm{i}}(j, k, l)\right) \\
= & \sum_{\substack{i=1 \\
N_{\text {pop }}}}^{N_{\text {pop }}}\left(-d_{\text {attract }} e^{\left(-w_{\text {attract }} \Sigma_{m=1}^{p}\left(\Theta_{\mathrm{m}}-\Theta_{\mathrm{m}}^{i}\right)^{2}\right)}\right) \\
+ & \sum_{i=1}\left(h_{\text {repel }} e^{\left(-w_{\text {repel }} \Sigma_{m=1}^{p}\left(\Theta_{\mathrm{m}}-\Theta_{\mathrm{m}}^{i}\right)^{2}\right)}\right)
\end{aligned}
$$

The health value $J_{\text {health }}$ of a bacteria $i$, given by equation (24), indicates how much nutrient it accumulates during the chemotaxis process. This value is used to select bacteria in the breeding stage.

$J_{\text {health }}^{i}=\sum_{j=1}^{N_{c h}+1} J(i, j, k, l)$ 


\section{International Journal of Innovations in Engineering and Science, www.ijies.net}

Reproduction: Healthier bacteria that have accumulated more nutrients are more likely to reproduce. E. coli bacteria are prokaryotic bacteria and reproduce asexually, making a copy of the chromosome and dividing the cell in two, without mutations. Conversely, bacteria that absorbed less nutrients or failed to avoid toxins are eliminated.

To model this process, after all the stages of chemotaxis, the health values of all bacteria, given by the value $J_{\text {health }}$, are ordered in an increasing order. The set is divided into two and the half with the best health values survives, while the other half is replaced by the replica of the better half. The number of reproduction iterations is defined by the constant $N_{\text {rep }}$ initially adjusted..
Elimination and Dispersal: The environment in which bacteria are looking for food can change gradually or instantly, causing some individuals to spread to other regions during this change.

In the iterations of this process, each bacterium is eliminated with a probability and another is randomly placed in the search space. This process is performed by $N_{e d}$ iterations. A high value of $N_{e d}$ increases the complexity of the solution, but also allows for a better scan of the search space, decreasing the chance of the solution found being a great location. The value of $p_{e d}$ should not be large, as it would lead to an exhaustive search.

\section{A. Simulation Parameters}

\section{Simulation AND RESUlts}

Table 1: Simulation parameters

\begin{tabular}{|c|c|c|c|}
\hline Controller Type & $\boldsymbol{K}_{\boldsymbol{P}}$ & $\boldsymbol{K}_{\boldsymbol{I}}$ & $\boldsymbol{K}_{\boldsymbol{D}}$ \\
\hline P & 0.0574 & -- & -- \\
\hline PI & 0.0623 & 0.0138 & -- \\
\hline PID & 0.0891 & 0.0814 & 3.1239 \\
\hline
\end{tabular}

\section{B. Simulation Results}
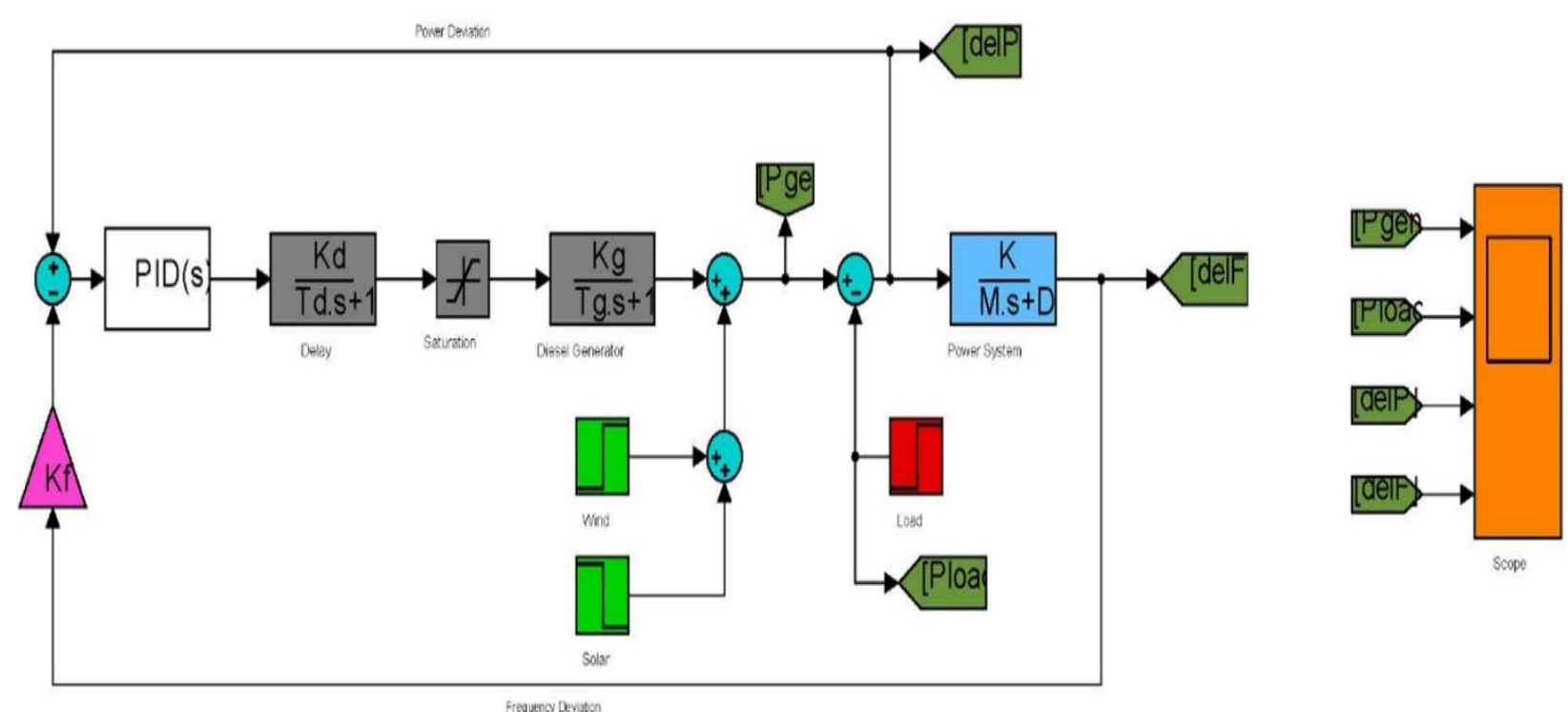

Fig 4- Simulink diagram for proposed load frequency controller 
International Journal of Innovations in Engineering and Science, www.ijies.net
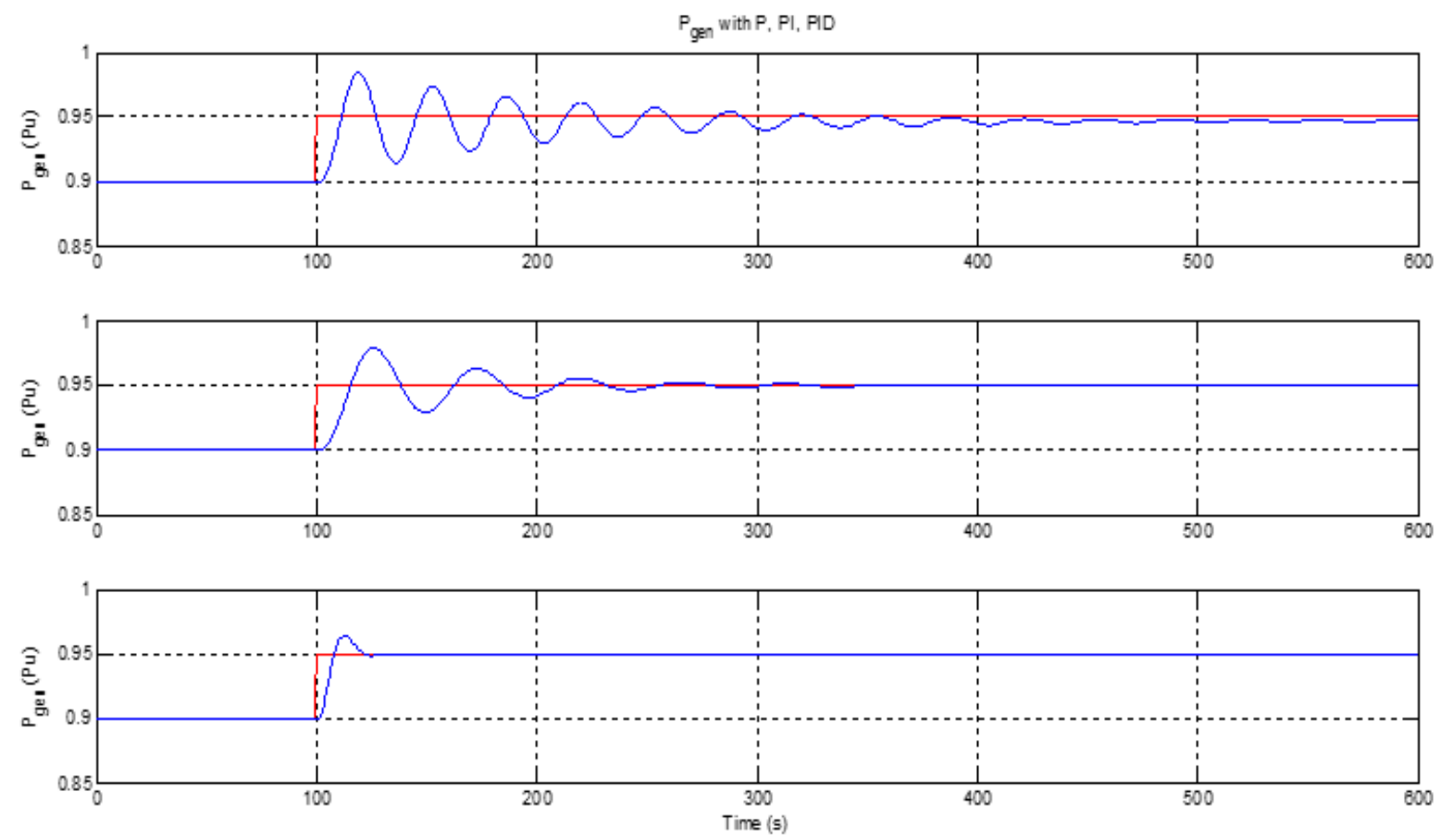

Fig 5-Power generation in system with P, PI and PID using Bacterial Foraging Optimization
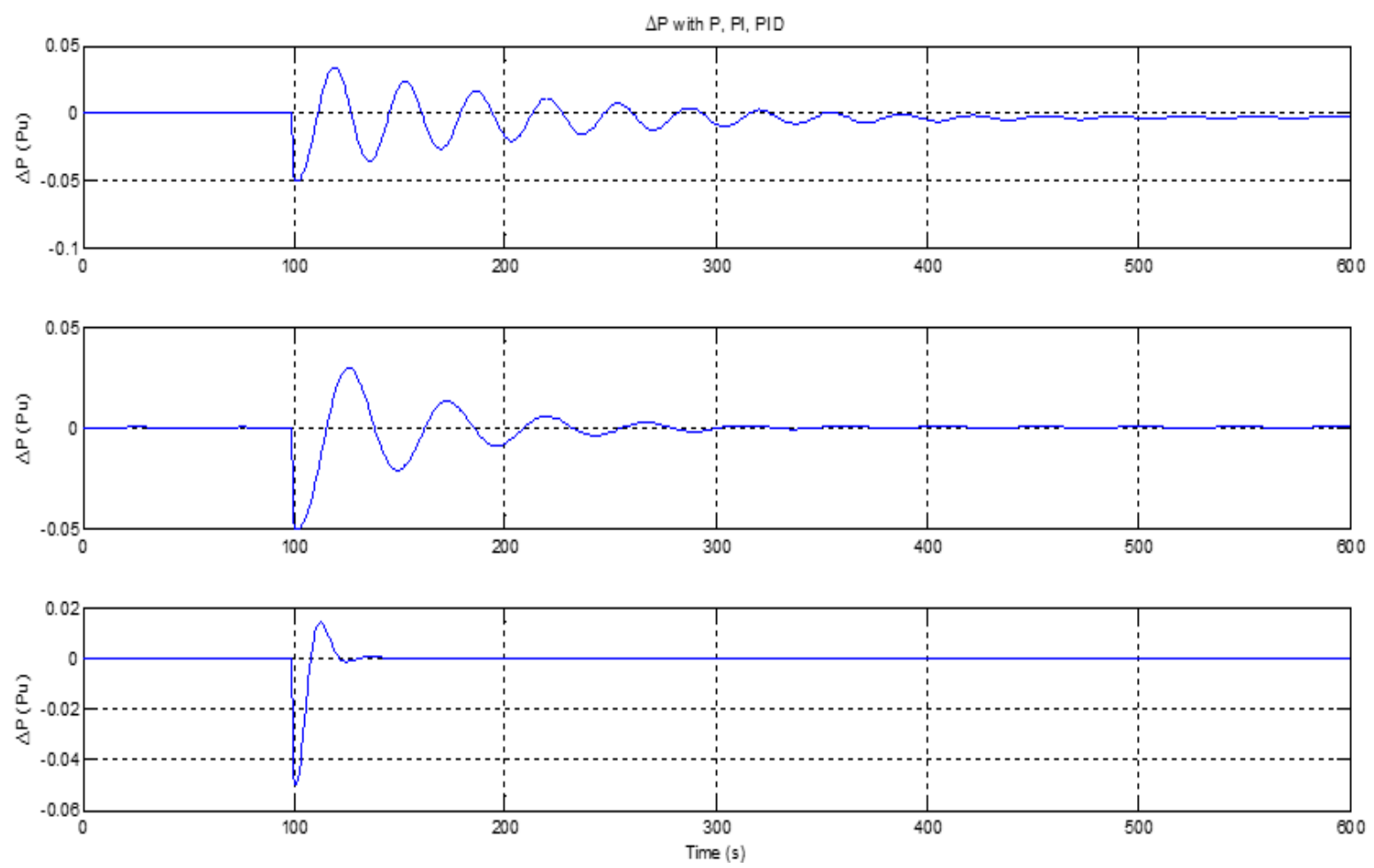

Fig 6-Power deviation in system with P, PI and PID using Bacterial Foraging Optimization 
International Journal of Innovations in Engineering and Science, www.ijies.net
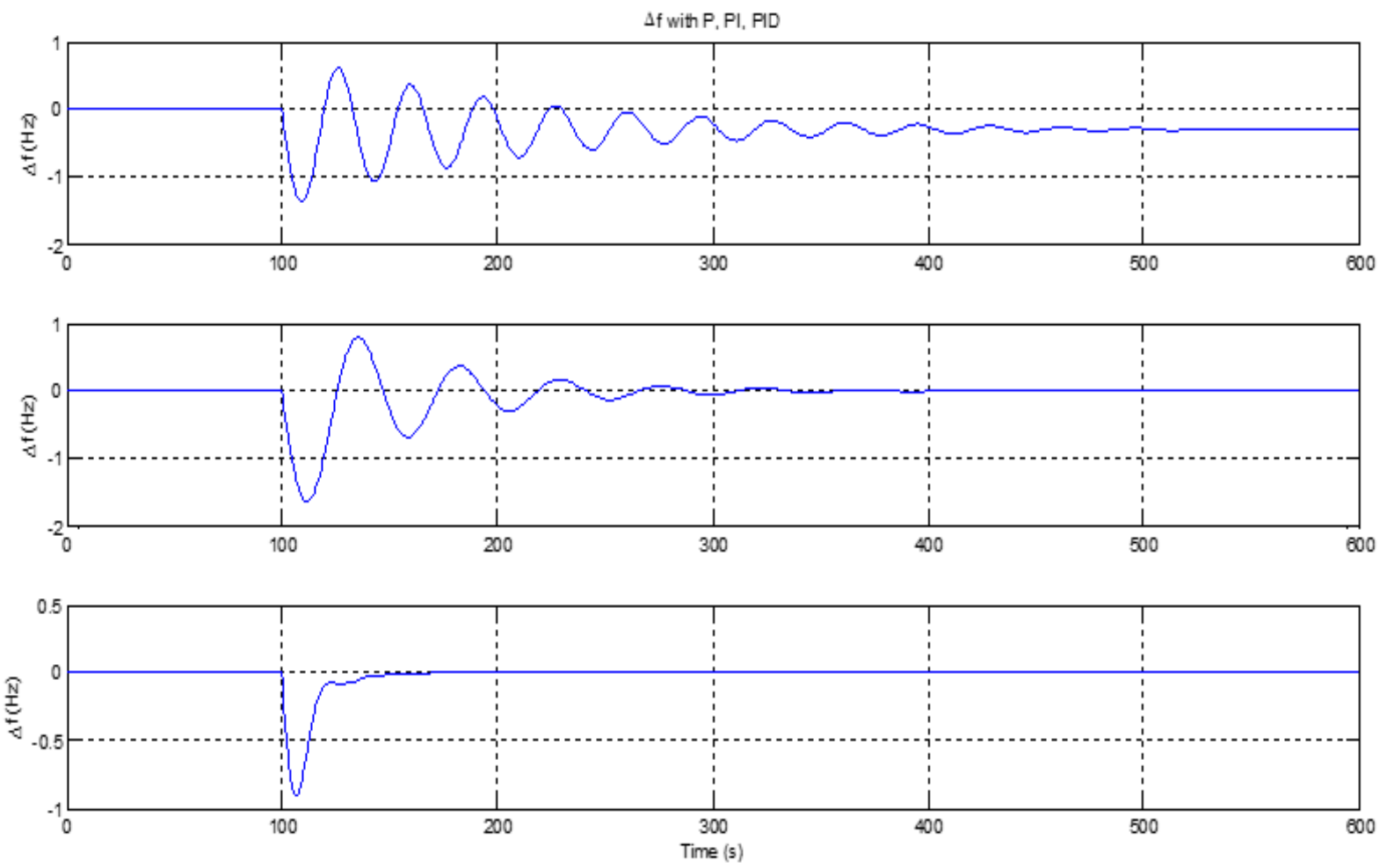

Fig 7- Frequency deviation in system with P, PI and PID using Bacterial Foraging Optimization
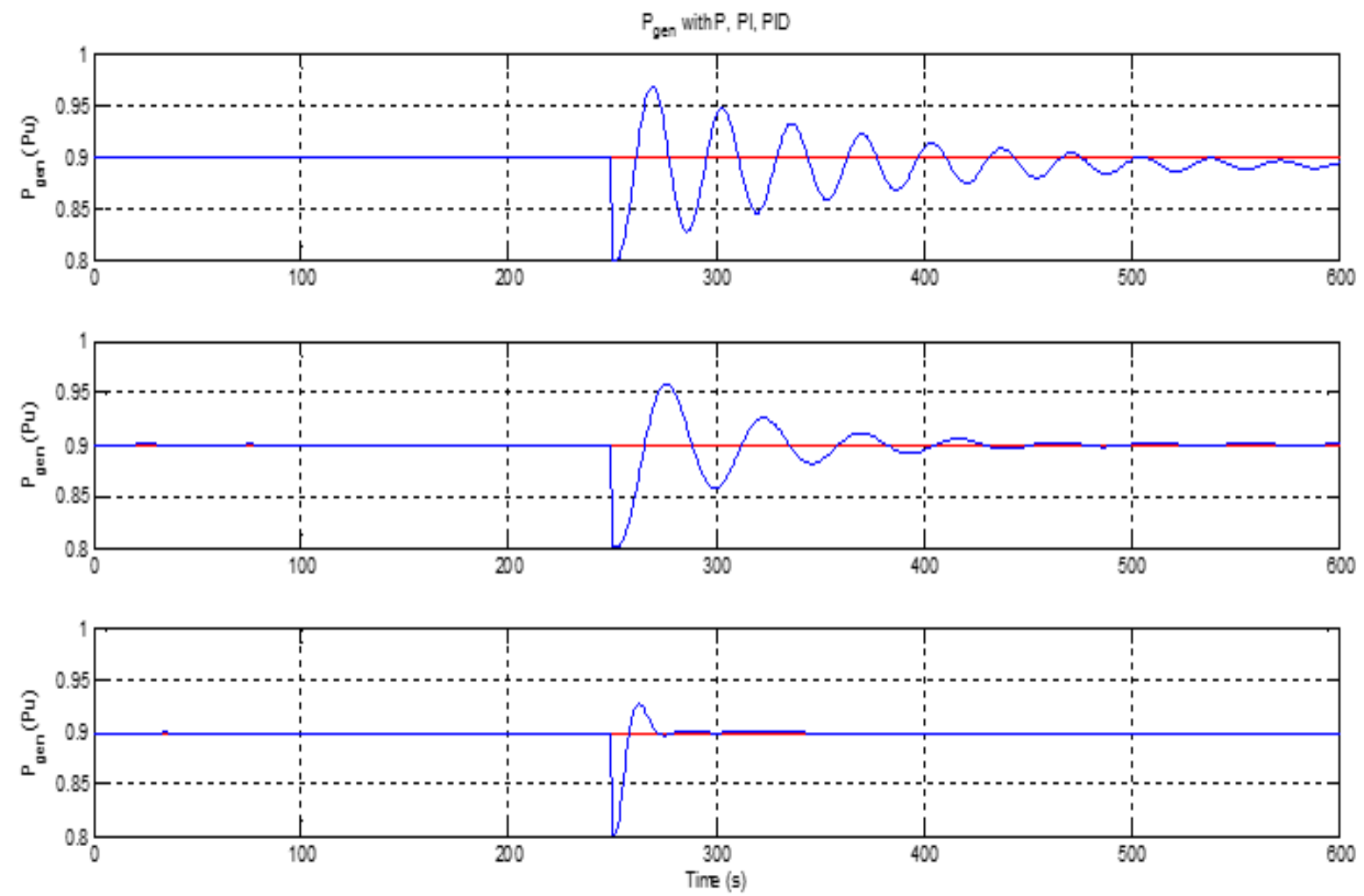

Fig 8-Power generation in system with P, PI and PID using Cultural Algorithm 
International Journal of Innovations in Engineering and Science, www.ijies.net
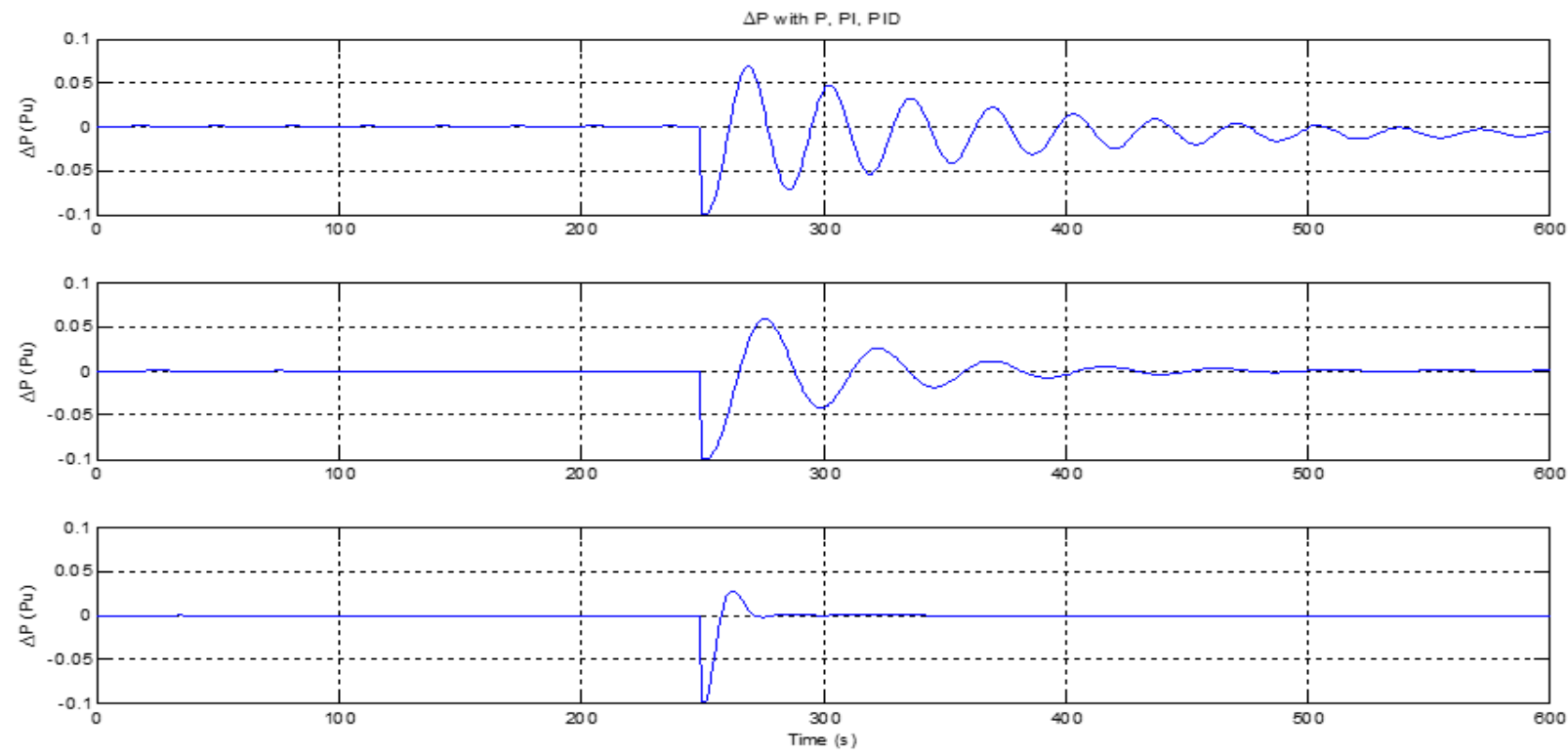

Fig 9- Power deviation in system with P, PI and PID using Cultural Algorithm
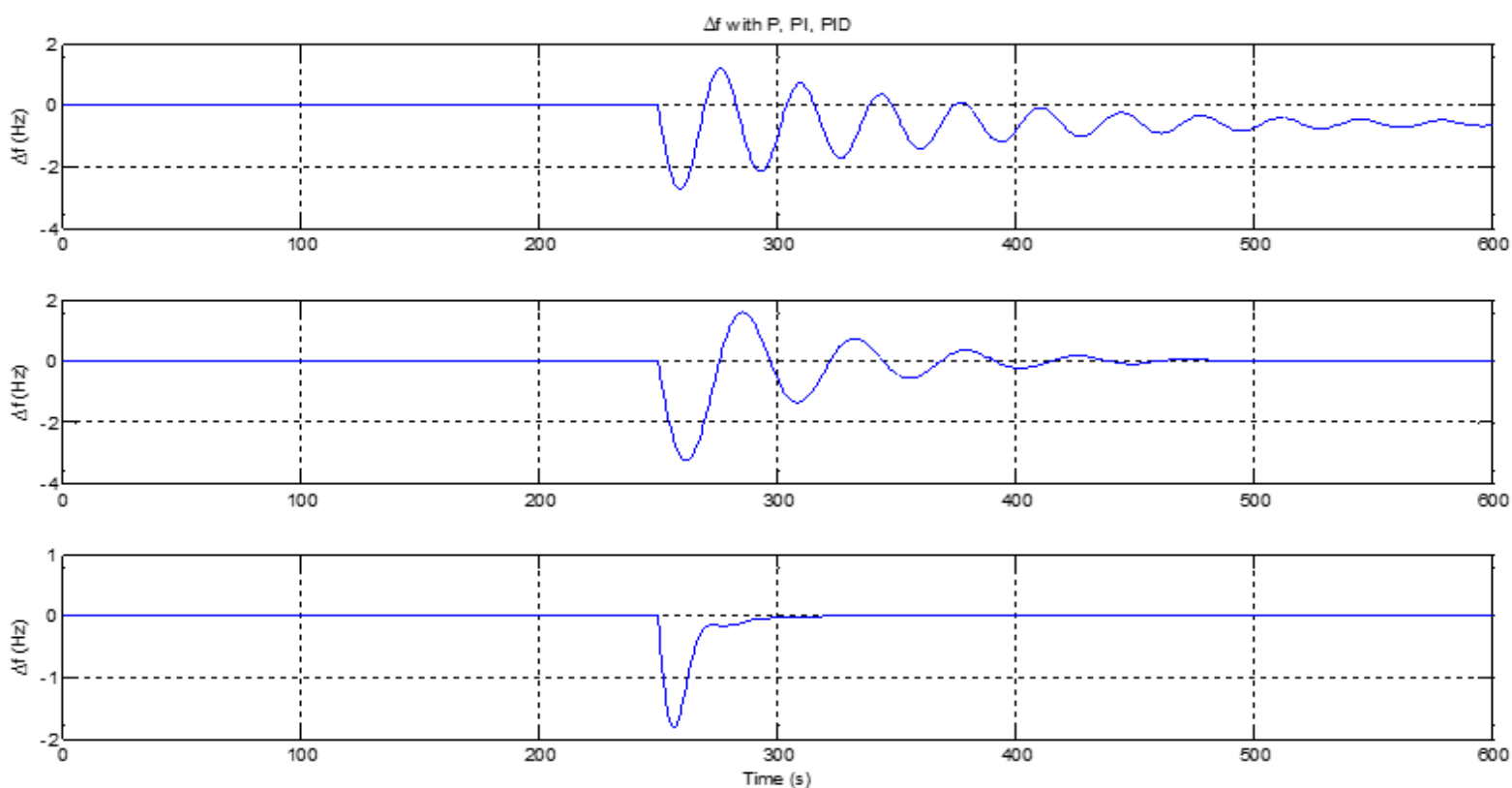

Fig 10-Frequency deviation in system with P, PI and PID using Cultural Algorithm

\section{III - CONCLUSION}

In this paper, the P, PI and PID controllers are designed for load frequency control in a two-area power system. For this purpose, the two-area power system was modeled in MATLAB 2019a and the response of P, PI and PID controllers in case of load change in the system was examined. According to these results, it is understood that the load frequency control with PID controller gives much better results than the traditional $\mathrm{P}$ and PI controllers in terms of maximum distortion. With the use of the objective function, the dynamic response of the system has been improved as a result of optimization, and the system control has been brought optimally and the efficiency of load-frequency control has been increased. However, with the use of cultural algorithm, the tuning process could be performed in a shorter time compared to BFOA algorithm due to the simplicity of the algorithm, the need for fewer lines of code, and the ability to converge to the result with less iteration. From analyzing the simulation result, it was found that the cultural algorithm outperforms the BFOA algorithm. 


\section{International Journal of Innovations in Engineering and Science, www.ijies.net}

\section{REFERENCES}

[1] Aguero, J.R., Khodaei, A. and Masiello, R., 2016. The utility and grid of the future: Challenges, needs, and trends. IEEE Power and Energy Magazine, 14(5), pp.29-37.

[2] Gamboa, S. and Orduña, E., 2015, February. Hierarchically distributed architecture for large-scale integrated WAMPAC system. In 2015 International Conference on Electronics, Communications and Computers (CONIELECOMP) (pp. 16-20). IEEE.

[3] Choudhary, K. and Singh, B., 2019. Load Frequency Control in Two Area Power Systems Integrated with SMES Combination using Fuzzy-PID and ANFIS Controller.

[4] Xu, H., Yao, J., Nan, G., Yu, Y.J., Yang, S.C. and ZHAI, M., 2018. New features of application function for future dispatching and control systems. Automation of Electric Power Systems, 42(1), pp.1-7.

[5] Zhang, W. and Fang, K., 2017. Controlling active power of wind farms to participate in load frequency control of power systems. IET Generation, Transmission \& Distribution, 11(9), pp.2194-2203.

[6] Abdulraheem, B.S. and Gan, C.K., 2016. Power system frequency stability and control: Survey. International Journal of Applied Engineering Research, 11(8), pp.5688-5695.

[7] Özdemir, M.T., Öztürk, D., Eke, I., Çelik, V. and Lee, K.Y., 2015. Tuning of optimal classical and fractional order PID parameters forAutomatic generation control based on the bacterial swarm optimization. IFACPapersOnLine, 48(30), pp.501-506.

[8] Singh, K. and Shankar, G., 2016, March. PID parameters tuning using modified particle swarm optimization and its application in load frequency control. In 2016 IEEE 6th International Conference on Power Systems (ICPS) (pp. 1-6). IEEE.

[9] Gheisarnejad, M., 2018. An effective hybrid harmony search and cuckoo optimization algorithm based fuzzy PID controller for load frequency control. Applied Soft Computing, 65, pp.121-138.

[10] Dhillon, S.S., Lather, J.S. and Marwaha, S., 2016. Multi objective load frequency control using hybrid bacterial foraging and particle swarm optimized PI controller. International Journal of Electrical Power \& Energy Systems, 79, pp.196-209.

[11] Abo-Elyousr, F.K., 2018, December. Load frequency controller with virtual inertia generator for interconnected power systems via artificial bee colony. In 2018 Twentieth International Middle East Power Systems Conference (MEPCON) (pp. 367-372). IEEE.

[12] Abd-Elazim, S.M. and Ali, E.S., 2018. Firefly algorithm-based load frequency controller design of a two area system composing of $P V$ grid and thermal generator. Electrical Engineering, 100(2), pp.12531262.

[13] Safi, S.J., Tezcan, S.S., Eke, I. and Farhad, Z., 2018. Gravitational search algorithm (GSA) based PID controller design for two area multi-source power system load frequency control (LFC). Gazi University Journal of Science, 31(1), pp.139-153.

[14] Barisal, A.K., 2015. Comparative performance analysis of teaching learning based optimization for automatic load frequency control of multi-source power systems. International Journal of Electrical Power \& Energy Systems, 66, pp.67-77.

[15] Guha, D., Roy, P.K. and Banerjee, S., 2016. Application of krill herd algorithm for optimum design of load frequency controller for multi-area power system network with generation rate constraint. In Proceedings of the 4th International Conference on Frontiers in Intelligent Computing: Theory and Applications (FICTA) 2015 (pp. 245-257). Springer, New Delhi.

[16] Alam, M.S., Singh, A. and Guha, D., 2016, January. Optimal solutions of load frequency control problem using oppositional krill herd algorithm. In 2016 IEEE First International Conference on Control, Measurement and Instrumentation (CMI) (pp. 6-10). IEEE.

[17] Pandey, S.K., Mohanty, S.R. and Kishor, N., 2013. A literature survey on load-frequency control for conventional and distribution generation power systems. Renewable and Sustainable Energy Reviews, 25, pp.318-334.

[18] Díaz-González, F., Hau, M., Sumper, A. and GomisBellmunt, O., 2014. Participation of wind power plants in system frequency control: Review of grid code requirements and control methods. Renewable and Sustainable Energy Reviews, 34, pp.551-564.

[19] Mohanty, B., 2015. TLBO optimized sliding mode controller for multi-area multi-source nonlinear interconnected AGC system. International Journal of Electrical Power \& Energy Systems, 73, pp.872-881.

[20] Shiva, C.K. and Mukherjee, V., 2015. Automatic generation control of interconnected power system for robust decentralized random load disturbances using a novel quasi-oppositional harmony search algorithm. International Journal of Electrical Power \& Energy Systems, 73, pp.991-1001.

[21] Ali, E.S. and Abd-Elazim, S.M., 2010. Optimal PID tuning for load frequency control using bacteria foraging optimization algorithm. ACE, 2, p.1.

[22] Panda, S., Mohanty, B. and Hota, P.K., 2013. Hybrid BFOA-PSO algorithm for automatic generation control of linear and nonlinear interconnected power systems. Applied Soft Computing, 13(12), pp.47184730.

[23] Oozeer, M.Y. and Ramjug-Ballgobin, R., 2018, November. Optimization of Load Frequency Control 
Vol. 6 , No. 11, 2021, PP. 8-20

\section{International Journal of Innovations in Engineering and Science, www.ijies.net}

for Non-linear System. In International Conference on Emerging Trends in Electrical, Electronic and Communications Engineering (pp. 34-44). Springer, Cham.

[24] Song, H.M., Ibrahim, W.I. and Abdullah, N.R.H., 2015. Optimal load frequency control in single area power system using PID controller based on bacterial foraging \& particle swarm optimization. ARPN Journal of Engineering and Applied Sciences, 10(22), pp.10733-10739.
[25] Yalçin, E., Çam, E. and Lüy, M., 2010, December. Load frequency control in four-area power systems using PID controller. In National Conference on Electrical, Electronics and Computer Engineering ( $p p$. 72-77). IEEE.

[26] Sathya, M.R. and Ansari, M.M.T., 2015. Load frequency control using Bat inspired algorithm based dual mode gain scheduling of PI controllers for interconnected power system. International Journal of Electrical Power \& Energy Systems, 64, pp.365-374. 